\title{
El análisis de un film y el psicoanálisis
}

\author{
Dimitri Weyl* \\ Université Paris 7
}

Recibido: 16 de diciembre 2016; aceptado: 10 de febrero 2017

Resumen

Desde la mirada psicoanalítica, el arte cinematográfico se comprende -la mayor parte del tiempo- sea desde una lógica de psicoanálisis aplicado, sea en términos "isomórficos". Eso limita el aporte que la confluencia entre cine y psicoanálisis puede generar cuando a esos dos campos se los reconoce en su singularidad y potencial respectivos.

Este artículo se propone identificar sintéticamente lo que se revela esencial en un proceso de investigación para que el análisis fílmico pueda ser lo más fructífero posible.

Walter Benjamín vio muy tempranamente que el psicoanálisis y el cine habían abierto campos de la mirada y de la escucha de lo que hasta entonces no podía ser visto ni oído. Y que esos campos podían ser poderosamente complementarios. El lenguaje cinematográfico -cuando se lo reconoce en su plena potencia- permite identificar efectos de realidad como ningún otro material lo hace. En consecuencia, nuestra hipótesis es que ligar armoniosamente la mirada cinematográfica a la mirada psicoanalítica implica abrir una "doble distancia focal". Dos distancias focales que cuando confluyen tienden a ligar lo invisible con lo visible. Lo invisible de las problemáticas inconscientes con lo visible de la imagen-movimiento.

Palabras clave: Análisis fílmico - Cine - Psicoanálisis - Imagen-movimiento

\begin{abstract}
From a psychoanalytical point of view, the cinematographic art can be understood - most of the time- either from the logic of applied psychoanalysis or as isomorphic terms. This limits the contribution that the combination of film and psychoanalysis can be made when both those fields are given recognition in their power and singularity. The purpose of this article is to identify what is revealed as essential in an investigation process to make film analysis the most useful as possible. From an early time, Walter Benjamin noticed that both psychoanalysis and film had opened fields of the senses that, up until then, could not be seen or heard; and that both of these fields, sight and sound combined, could be very powerful. Cinematographic language - when recognized in its full potential - can capture the effects of reality like no other material can. Because of this, our hypothesis is to consider that bonding the psychoanalytical point of view with the cinematographic point of view can open a "double focal distance". These two focal distances, when they converge together, tend to bond what can be seen with what can't be seen; the invisibility of the unconscious problematic, with the visibility of image and movement.
\end{abstract}

Keywords: Film analysis | Cinematography | Psychoanalysis | Image-Movement

¿Cómo pueden, en el análisis de un film, confluir cine y psicoanálisis en sus más altos potenciales?

¿Cómo puede el teórico, psicoanalista o relacionado con el psicoanálisis, operar una confluencia con la obra fílmica que permita avances teóricos? A nuestro entender, hay muy poco escrito específicamente sobre esta cuestión. Lo cual es tanto más llamativo puesto que los trabajos en torno a la articulación entre cine y psicoanálisis son muy numerosos, y los análisis de películas con herramientas psicoanalíticas resultan incluso excesivos. La mayoría de las veces, esos análisis de películas provienen del psicoanálisis aplicado, con lo cual dejan poco lugar a la singularidad del aporte cinematográfico, lo que reduce su potencial.
En un pasaje significativo de su célebre texto La obra de arte en la época de su reproductibilidad técnica, ${ }^{1}$ Waler Benjamin reconoció muy tempranamente la transformación operada por esos dos descubrimientos, cada uno en su singularidad. Ese texto parece ser fundacional: Benajmin escribió allí que esos dos descubrimientos sincrónicos revolucionaron la mirada del hombre, la mirada que el ser humano podía dirigir hacia sí mismo y hacia sus semejantes.

Este artículo propone identificar, sintéticamente, lo que se revela esencial para que el análisis de películas sea lo más fructífero posible. Se trata de identificar lo que impide y lo que permite que pueda operarse una composición entre esas dos miradas dirigidas hacia el ser humano.

* dimitriwey@free.fr 
La fuerza de esa unión, para desplegarse al máximo de su potencialidad, involucra cuestiones de reconocimiento y de distancia justa. Aparentemente, en el análisis fílmico, a esa fuerza de la unión se le dificulta desplegarse por al menos tres razones fundamentales: por un peso excesivo del psicoanálisis en el cine; contrariamente, por exceso de proximidad, de confusión; y quizás, sobre todo, por falta de reconocimiento de lo que constituye los fundamentos del arte cinematográfico. ${ }^{2}$

In fine, consideramos que ligar esas dos miradas es tender hacia una "doble distancia focal" en la cual se opera una convergencia, una articulación de puntos de vista sobre el trabajo de lo visible y de lo invisible.

\section{El impasse del psicoanálisis aplicado y de la ilusión de gemelidad}

En esa búsqueda de una confluencia entre cine y psicoanálisis, desde el punto de vista analítico, deberían identificarse de entrada dos escollos: por un lado, la posición de superioridad; por el otro, el exceso de proximidad.

Acordamos con Mireille Berton cuando escribe, en su reciente artículo "el par cine-psicoanálisis, así como su corolario película-ensueño, continúan actualmente siendo aprehendidos en términos de isomorfismo y subordinación del primero al segundo."

Unos años más tarde, los hermanos Pierre-Jean Bouyer, guionista, y Sylvain Bouyer, psicoanalista y académico, concluían su artículo "Cinéma et psychanalyse" (“Cine y psicoanálisis”) de esta forma: “Queda pendiente quizás emprender un trabajo sobre las relaciones complejas que se tejen entre el psicoanálisis y el cine, más allá de la sola aplicación de los conceptos psicoanalíticos en el séptimo arte". ${ }^{4}$

En efecto, parece que lo que se practica la mayor parte del tiempo, en el marco del análisis fílmico, es del orden del psicoanálisis aplicado, lo que resulta problemático en más de un aspecto.

Recordemos que esos dos términos unidos, "psicoanálisis" y "aplicado", plantean problemas tanto en la terminología como en el uso que se pueda hacer de ellos. Aplicar supone "poner (una cosa) sobre (otra) de manera que la toque, recubra, adhiera o deje una impresión"5. Se trata de colocar, apoyar, exponer, extender, superponer, incluso cubrir.En ese sentido, concordamos plenamente con la crítica realizada por Sophie de Mijolla-Mellor. ${ }^{6}$
No solo esa terminología supone "un trasplante fuera de su lugar de origen" -la cura que es origen del método-, lo que hace correr el riesgo de un "uso abstracto, incluso mecanicista", 7 sino sobre todo que ella puede significar el dominio de un saber constituido sobre un objeto pasivo que no tendría, en consecuencia, ningún efecto a cambio, ningún efecto de sorpresa.

En la peor de esas manifestaciones, el psicoanálisis aplicado produce un efecto de recubrimiento abstracto, una relación de dominación, de potencial confusión entre el concepto y la cosa, así como una asignación del objeto a la pasividad: el psicoanálisis sabe y con ese saber va a revelar lo invisible del relato.

Con ese posicionamiento epistemológico y metodológico, en el mejor de los casos se aclara el concepto, lo que a veces puede ser heurístico; y en el peor se lo corrompe y se lo convierte en comodín, ya no está allí para responder a una pregunta, según la definición que da Deleuze $^{8}$, sino para asignar una respuesta preconcebida. Por lo tanto, es posible pasar por alto lo que puede aportar la obra en su expresión singular, eclipsar su "actividad" y hasta su propia razón de ser; a saber, lo que ella tiene de inefable, de realidad, de nuevo, de inesperado y de inexplorado.

Por eso consideramos esencial salir de esa lógica de la “aplicación”, para acoger al cine en sus "diferentes modalidades de expresiones que reflexionan sobre el sentido de lo humano" y así considerar las "interacciones" -según la expresión de Sophie de Mijolla-Mellor- entre psicoanálisis y cine, y el aporte específico y eminentemente singular de este último.

El otro escollo es el que se relaciona con la ilusión de gemelidad.

Cierto número de investigaciones sobre el cine y el psicoanálisis han trabajado las contigüidades que pueden establecerse entre esos dos campos. Se trata de afinidades electivas de vocabulario y de procedimientos: proyección, sesión, pantalla, identificación, representación; la sala de cine donde se proyectan los sueños que se analizan y que sería comparable al proceso analítico, etc. Todos esos procesos no deben, evidentemente, denigrarse in toto, en especial cuando trabajan sobre la analogía pero reconociendo los límites de esta. A contrario, el riesgo se encuentra en un exceso de proximidad, en una forma de ilusión de gemelidad que genera un régimen de confusión.

En esta línea de razonamiento, creo que es posible darle la razón a Freud en un punto: "Mi principal objeción continúa siendo que no considero posible representar 
plásticamente -de manera respetable- nuestras abstracciones." Aunque "nuestras abstracciones" equivalgan o remitan al inconsciente, parece que en efecto, al igual que ningún otro arte, el cine no puede representar-stricto sensu- el inconsciente. Siempre hay y habrá, muy probablemente, algo de irrepresentable en el inconsciente.

La proximidad que se puede establecer entre el arte cinematográfico y los procesos primarios no le da sin embargo el poder de plasmar el inconsciente. Pero eso no significa que el cine no esté en condiciones de captar, de permitir que se vea y se sienta algo de los conflictos inconscientes de un modo que le es absolutamente intrínseco.

Así, aunque el paralelismo más establecido es el del sueño, que vale también para el ensueño diurno en el que uno "se hace su propia película", analizar un film como se analizaría un sueño es confundir una producción del inconsciente con la producción de una obra de creación, $y$ de investigador, que es -en proporción significativa-consciente. Eso no excluye, por supuesto, que los procesos de condensación y de desplazamiento sean esenciales para la obra fílmica.

En suma, ¿no remiten las dos barreras que acabamos de nombrar a lo que puede impedir la potencia de cualquier unión? Una distancia excesiva que no reconoce la potencia intrínseca del cine, su singularidad y la manera en que puede interrogar, cuestionar, sorprender, incluso modificar y enriquecer la mirada psicoanalítica; una proximidad exagerada, en la cual el régimen de confusión tiende a disolver la singularidad, y por lo tanto la potencia de cada uno de esos campos.

De tal modo, la pregunta a la que lleva este primer capítulo es la siguiente:

¿De qué manera, y evitando volver a una relación de confusión, identificar puntos de ligazón sin aplicar, imponer teorías psicoanalíticas, sometiendo así la obra cinematográfica a una teoría preexistente y por eso congelada, para considerar -según Freud en la Gradivalas obras cinematográficas como "aliados" y no como objetos? ${ }^{11}$

Juega aquí, como en toda situación de unión, la problemática de la separación justa, de la distancia apropiada, lo que supone reconocer-suficientemente- la alteridad $y$ los puntos de unión de las dos entidades.

Eso implica previamente seguir la obra "como" se seguiría a un paciente. En este caso, la analogía con la clínica se sostiene, para dejarse sorprender estando en condiciones de reconocer lo que une y lo que es del orden de una alteridad irreductible. Probablemente este último punto, para el investigador psicoanalista, es el más problemático y fructífero a la vez.

\section{Cineastas e investigadores}

A la gemelidad, como a la superioridad, preferimos los mellizos: tanto el psicoanálisis como el cine permiten ver, pero no en el sentido de la vista sino de la mirada $a^{12}$, de la modificación de miradas.

Sigamos la metáfora: ambos dejan ver de manera exacerbada lo que muchas veces no podía ser visto. Uno, a través de lo patológico, permite ver mejor lo "normal", la psique en su conjunto; el otro, por la imagen-movimiento, ${ }^{13}$ permite ver y volver a ver los movimientos del cuerpo-psique ${ }^{14}$-y las interacciones entre los cuerpos-psique- a menudo inasibles en la realidad.

\subsection{En el principio eran los cuerpos y el nacimiento de dos miradas}

Hay un punto de origen "común" a esos dos descubrimientos, que se señala poco. Ambos nacieron por el interés en los misterios de los cuerpos cuya elucidación escapaba a las ciencias de ese entonces.

En la misma época en que Freud asiste a las famosas puestas en escena de cuerpos organizadas por Charcot, dos de los principales precursores del cine, Muybridge y Marey se dedicarán a penetrar el familiar misterio de los movimientos del cuerpo. Marey es un médico y psicólogo francés interesado por todo. Muybridge es fotógrafo, en una época en que eso oscilaba entre la ciencia y el arte. Ambos se harán famosos por sus trabajos de descomposición de los movimientos del cuerpo de los hombres y de los animales, lo que permitirá a los investigadores de la época darse cuenta de que no se podía identificar claramente los movimientos de los cuerpos antes de esa iluminación que ofrece la imagenmovimiento. ${ }^{15}$

Hay en principio dos miradas sobre el hombre, sobre el cuerpo de los hombres, que intentan penetrar algo a través de puntos de vista que son, de cierto modo, opuestos. Uno, el cine, desde su prehistoria, intentará penetrar algo del movimiento de los cuerpos con la creación de un instrumento que ilumina lo visible para verlo de una manera que antes no se podía. Eso se irá desarrollando hasta convertirse en un arte. El otro, el psicoanálisis, va a anclar su descubrimiento en la ininteligibilidad de ciertos 
movimientos del cuerpo, los de la histérica, iluminándolos con claves invisibles que los determinan. ${ }^{16}$

En su célebre texto, Benjamin plantea la ruptura que el cine va a operar en la relación que el hombre podía tener con la imagen y la representación de la realidad, en especial porque introduce el paralelo que va a establecer entre cine y psicoanálisis con la siguiente frase:

"La representación cinematográfica de la realidad es para el hombre actual incomparablemente más importante, puesto que garantiza, por razón de su intensa compenetración con el aparato, un aspecto de la realidad despojado de todo aparato que ese hombre está en derecho de exigir de la obra de arte. ${ }^{17}$

Benjamin, al considerar especialmente el trabajo de ligazón entre ciencia y arte que el cine pudo operar según él-18, va a establecer un fuerte paralelismo entre psicoanálisis y cine (sobre todo en el capítulo XIII) puesto que esos dos descubrimientos abrieron un campo de comprensión del ser humano y de sus conflictos, de sus movimientos psíquicos y corporales, que no existían hasta entonces. ${ }^{19}$

En el principio era pues la realidad de los cuerpos: lo que no puede ser captado por lo simbólico ni por lo imaginario. Uno tratará de descifrar esa realidad desde lo simbólico, el otro desde lo imaginario, a través de la imagen-movimiento, y ambos nacen de esa confrontación a la realidad, a un imposible, a un irrepresentable, a un sinsentido: no hay metapsicología sin clínica, no hay cine sin cuerpo real. ${ }^{20}$

Ambos permitirán mirar y escuchar lo que no podía ser visto ni oído hasta entonces.

\subsection{El Proceso de investigadores de los cineastas}

"El cine ha enriquecido nuestro mundo perceptivo con métodos que de becho se explicarían por los de la teoría freudiana. Un lapsus en la conversación pasaba hace cincuenta años más o menos desapercibido. Resultaba excepcional que de repente abriese perspectivas profundas en esa conversación que parecía antes discurrir superficialmente. Pero todo ha cambiado desde la Psicopatología de la vida cotidiana. Esta ba aislado cosas que antes nadaban inadvertidas en la ancha corriente de lo percibido. Y las ha becho analizables. Tanto en el mundo óptico, como en el acústico, el cine ha traído consigo una profundización similar de nuestra apercepción." 21

En nuestra búsqueda de un efecto de encuentro, el primer punto de unión, fundamental, se funda en el reconocimiento de que los cineastas que producen una obra son investigadores. En primer lugar, entiendo por obra lo que no es cautivo del cine industrial, de la sola distracción, que no deriva de lo que Debord denuncia en La sociedad del espectáculo ${ }^{22}$; a saber, lo que genera interrogantes, puntos oscuros que se dejan ver y sentir pero dejando al espectador en libertad ${ }^{23}$. El cine industrial tiende ante todo a vender al mayor número de personas, y para eso apunta a volver al espectador confortablemente cautivo ${ }^{24}$. La obra de arte cinematográfica, o la obra de autor ${ }^{25}$, proviene de un trabajo de investigación $y$ de emancipación.

Varios de estos cineastas -que retienen nuestra atención en especial- se consideran investigadores de las relaciones humanas y la cosa psíquica: Bergman, Buñuel, Losey, Pasolini, von Stroheim, Brisseau, Mankiewicz, para citar solo algunos que se definieron a sí mismos en ese sentido.

En efecto, von Stroheimz construirá su obra en los conflictos armados: "Intento grabar mis películas en la trama rugosa de los conflictos bumanos"26

Mankiewicz, que estudió psicología, construyó casi la totalidad de su obra sobre problemáticas psicológicas que articulan poder y narcisismo. ${ }^{27}$

Otros se abocaron al continente todavía oscuro. Brisseau, cuando dirige Los ángeles exterminadores (2006), se ocupa de filmar mujeres en escenas eróticas, sin juego previo, que van directo al orgasmo. Fuera y dentro de la película (mise en abyme), Brisseau explica esta búsqueda contra viento y marea (escándalos y juicios): lo que lo motiva, sobre todo, es poder identificar, captar, comprender algo del orgasmo femenino denunciándolo con la imagen-movimiento. A pesar del escándalo que eso va a generar, de los juicios que intentarán hacerle, de las grandes dificultades para poder producir la película, él seguirá adelante. La pulsión epistemológica se impone a las prohibiciones, y se alía a la pulsión escópica.

Pasolini, para la dirección de Edipo Rey (1967), se nutrió del saber psicoanalítico con el fin de "reproyectarlo" de un modo sensible. "Apliqué las nociones psicoanalíticas tales como yo las sentí y es así como reproyecté el psicoanálisis en el mito". ${ }^{28}$

Así como Pasolini, entre otros, dialogó con el psicoanálisis durante sus procesos de creación, podríamos hacer dialogar a Freud, de una cita a otra, con algunos cineastas. El objetivo sería subrayar que lo que Freud pudo identificar en los artistas acerca de la riqueza de sus procesos de creación, y de los escritores en particular, proviene también del cine que el padre del psicoanálisis observaba con ojo suspicaz.

Freud, en efecto, habló muchas veces del trabajo artístico como "precursor" del científico, y en ese sentido, 
lo consideró no un objeto de predilección sino un valioso "aliado del psicoanálisis". "Ahora bien, los poetas son unos aliados valiosísimos y su testimonio ha de estimarse en mucho, pues suelen saber de una multitud de cosas entre cielo y tierra con cuya existencia ni sueña nuestra sabiduría académica. (...) Y en la ciencia del alma se han adelantado grandemente a nosotros, hombres vulgares, pues se nutren de fuentes que todavía no hemos abierto para la ciencia." ${ }^{29}$

Buñuel parece responder y completar la cita de Freud extraída de la Gradiva, a la vez que señalar algunas singularidades propias del séptimo arte y del poder emocional de la imagen: "El cine es el mejor instrumento para expresar el mundo de los sueños, de las emociones, del instinto, y parece haber sido inventado para expresar la vida del subconsciente cuyas raíces penetran tan profundamente en la poesía". ${ }^{30}$

Para Luis Buñuel, entonces, el cine fue inventado para expresar -y no representar- los movimientos del inconsciente, cuyas "raíces", las "fuentes" misteriosas para la "ciencia" que evocaba Freud, están en relación directa con la "poesía”, o quizás, lo que llamaremos más adelante la poiética.

Siempre en la Gradiva, Freud escribe: "Nuestro procedimiento consiste en la observación consciente de los procesos anímicos anormales en otras personas a fin de poder colegir y formular sus leyes. El poeta procede de otro modo; dirige su atención a lo inconsciente dentro de su propia alma, espía sus posibilidades de desarrollo y les permite la expresión artística en vez de sofocarlas mediante una crítica consciente. De esa manera averigua desde sí lo que aprendemos en otros, las leyes a que debe obedecer el quehacer de eso inconsciente; pero no le hace falta formular esas leyes, ni siquiera discernirlas con claridad: debido a la actitud tolerante de su inteligencia, ellas están encarnadas en sus creaciones." ${ }^{31}$

Por su parte, Bergman podría razonar con Freud, dejando entender también una especificidad cinematográfica.

"Se hizo evidente que lo cinematográfico se habia convertido en mi medio de expresión. Me hacía escuchar en una lengua que no pasaba por el lenguaje que me faltaba, por la música que no dominaba, por la pintura que me dejaba frío. Tenía de pronto una posibilidad de relacionarme con el mundo a mi alrededor en una lengua que se habla directamente de alma a alma en giros que, casi voluptuosamente, se sustraen al control del intelecto. De ese modo, (...) durante veinte años, sin cansarme, con una especie de furor, transmití sueños, sensaciones, fantasías, gritos de locura, neurosis, estasis de la fe y puras mentiras." ${ }^{32}$
Picasso podría completar a su vez: "El arte es una mentira que nos permite develar la verdad". Dicho de otro modo, en arte, develar una verdad que avanza enmascarada es captarla a través de la ficción.

La ficción es una elaboración, nada más, y eso ya es mucho. Es un trabajo del pensamiento, de la imaginación creadora, a partir de datos, de materiales de vida utilizados y transformados por la construcción de una obra. ${ }^{33}$

No se trata por lo tanto de entrar en el pseudomisticismo de los "fundamentalistas del arte": los grandes autores no son magos en comunicación con lo divino. Tienen, por el contrario , una gran capacidad de elaboración, y de presentación.

\subsection{El imaginario creativo}

Esa emergencia de una forma-adecuada al fondotiene que ver con la poiética, es decir, con el imaginario creativo. ${ }^{34}$

$\mathrm{Si}$ ciertos cineastas intentan penetrar los misterios del psiquismo es para permitir que se vean y se sientan, pasando por lo que Cornelius Castoriadis llama la imaginación radical, creadora, específica para hacer emerger la poiética. Utilizo el término poiética para subrayar su dimensión intrínsecamente creadora (poiesis), a la vez que para diferenciarla de lo que se relaciona con la investigación estetizante. Por lo tanto, entiendo por poiética una acción que desemboca en una creación nueva, sirviéndose del imaginario creativo.

Lo que Castoriadis llama imaginario creativo o radical es la "facultad originaria de plantear o de ofrecer, en la modalidad de la representación, una cosa y una relación que no están (que no están disponibles en la percepción o nunca lo estuvieron) [...] El imaginario del cual hablo no es imagen $d e$. Es creación incesante y esencialmente indeterminada de figuras / formas / imágenes, a partir de las cuales solo puede ser cuestión de "algo" 35 , de una emergencia. El imaginario creativo conjuga los procesos primarios, pasando por la condensación y el desplazamiento, con las combinatorias que crean nuevos ordenamientos, es decir, surgimientos. No es propiedad exclusiva del artista, pero sí su principal fuente.

Por otra parte, podemos considerar legítimamente que Freud peca de exceso de modestia cuando parece restringir el trabajo de investigador del psicoanalista, y haciéndolo suyo, lo reduce a "sabiduría académica". De tal modo, cuando escribe esa frase, que recoge una dimensión esencial de todo lo que acabamos de 
esbozar: "Existe, en efecto, un camino de regreso de la fantasía a la realidad, y es... el arte" 36 , algo sabe. Freud convoca numerosas y eclécticas metáforas en su obra. "Lejos de ser una simple decoración formal, la potencia de creación metafórica en el texto freudiano es proporcional a la potencia de pensamiento: incluso es casi su síntoma." ${ }^{37}$ No es un gran secreto: todo gran pensador es artista, y todo gran artista es un pensador de envergadura. Nietzche, para quien el aforismo, la metáfora, eran un modo casi constante de expresión, es uno de los que más se aproximaban a una síntesis entre el pensador y el artista. Aquí, pues -en el seno del proceso de creación-, las fronteras se confunden y las paralelas se cruzan. Por supuesto, el trabajo de la poiética se pone en práctica intensamente en el proceso analítico, y sobre todo en los momentos de interpretación performativa. Y aunque en el trabajo de teorización la razón tiene el estrellato -por necesidad de orden y de inteligibilidad-, solo la poiética permite verdaderos avances, saltos cualitativos.

Dos procesos de los creadores, entonces, que en sus obras pasan, uno a través de la razón, sobre todo, para dar a comprender a través de la conceptualización y la teorización; el otro, a través del imaginario creativo, para hacer que se vea y se sienta. El teórico creaba conceptos; el artista, para retomar la teoría deleuziana, perceptos. ${ }^{38}$

Si bien trabajar en la combinación, armonización de la elaboración teórica con la poiética cinematográfica puede generar una gran potencia de entendimiento, es necesario para ello estar en condiciones de reconocer lo esencial de lo que constituye el lenguaje intrínsecamente cinematográfico, los componentes de su potencia creadora y expresiva. Una obra cinematográfica de ficción no se aprehende únicamente como un escrito, y menos como un discurso, pues eso sería un análisis de guion, y no de película.

Ese trabajo sobre la forma, de la forma en relación con el fondo, tiene su especificidad, y creemos que no reconocerlo es avanzar casi a oscuras, con una sola distancia focal.

\section{El lenguaje fílmico}

Nosotros, especialistas en la palabra, tendemos en el análisis fílmico a aferrarnos demasiado exclusivamente a ellas y al relato en detrimento de las imágenes y del lenguaje cinematográfico. Aunque en el proceso de creación hay que reconocer, generalmente ${ }^{39}$, tres tiempos de escritura: el guión (que incluye las story-board), la filmación (o rodaje) y el montaje, lo que debe ser objeto de análisis es claramente la entidad finalizada, la obra cinematográfica.

Simplifico acá los componentes de ese lenguaje en su quintaesencia y no pretendo -lejos estoy de esorealizar un trabajo exhaustivo sobre ese punto en el presente marco. ${ }^{40}$ Simplemente, se trata de identificar lo que se revela esencial para el análisis fílmico, y más particularmente desde nuestro campo.

\subsection{Los principales componentes}

Si seguimos a Deleuze, el primer componente fundamental del arte cinematográfico es la imagen-movimiento, es decir, una imagen que permite ver y sentir los movimientos, los encadenamientos sensitivo-motrices o los encadenamientos de actitudes y posturas. ${ }^{41}$

Esa noción de imagen-movimiento, que podría llamar también imagen cinemática, se revela esencial a nosotros puesto que toda investigación pone en juego la representación en movimiento. Toda investigación convoca algo que no es solo del orden de la representación de un hecho, una fotografía de un hecho, algo que se vería como estático, sino por el contrario, algo que está en movimiento perpetuo.

Los cineastas también son investigadores, a veces investigadores de la cosa psíquica pero que tienden -esencialmente- a capturar algo a través de la imagen-movimiento, de los movimientos de los cuerpos y de sus interacciones, de la creación de un espacio fenomenológico que permite ver y sentir los impulsos y conflictos humanos.

Ese lenguaje intrínsecamente cinematográfico se apoya pues en la imagen-movimiento, el encuadre fijo o en movimiento (panorámico y travelling) en planos que pueden ser cortos o largos, o también planos-secuencia, el montaje, la elipsis, el tratamiento del sonido y de la luz, el fuera de campo.

Por otra parte, se podría estimar legítimamente que el tratamiento del sonido ocupa un lugar tan esencial que sería quizás más justo hablar, en numerosas ocasiones, de imagen-movimiento-sonido.

Hay que considerar que la condensación juega un papel esencial en ese lenguaje y que cada uno de esos elementos antes citados, llamados modos de expresión, gramática cinematográfica o herramientas intrín- 
secas. Por eso, la condensación adquiere un carácter necesariamente significativo en el seno de una obra. Evidentemente, cada intención es necesaria y no contingente en arte, incluso la que uno atribuye al azar. Lo mismo sucede con el cine. Es obvio, por ejemplo, que uno no va al encuentro de una pintura o de una escultura de tal o cual maestro diciéndose que tal o cual elemento de la obra es contingente. Eso es igualmente válido para una obra cinematográfica: hay que considerar cada plano, cada encuadre, cada composición espacial, el uso del fuera de campo, cada elipsis, cada montaje, el tratamiento del sonido y de la luz, etc. como significativos y en relación, en $\log o s^{42}$, unos con otros.

Por lo tanto, no solo la condensación, que remite a la metáfora, sino también el desplazamiento, que remite a la metonimia, deben considerarse como "hiperactivos"43 en el arte cinematográfico. A saber, cada imagenmovimiento debe considerarse potencialmente sobresignificativa y poderosamente polisémica puesto que remite a otras cosas, a otros "significantes" en el seno de la obra, operando así desplazamientos que pueden desplegarse como rizomas. ${ }^{44}$

\subsection{El significante imaginario o no fonemático}

El trabajo de Christian Metz sobre lo que llama significante imaginario ${ }^{45}$, tendía a mostrar la especificidad de esa "unidad lingüística visible" en el arte cinematográfico.

Para quien quiera captar algo a través de la imagen, P'tit bal, cortometraje de Philippe Découflé, lo usa muy bellamente: no podría incluso ilustrarse de mejor manera, poéticamente, el lazo entre el significante y el significante imaginario. ${ }^{46}$

Como la materialidad del significante es diversa, este no es solo fonemático, puede pasar también por una imagen, una imagen-movimiento, un objeto, un color, o incluso por la expresión de un rostro. ${ }^{47}$

Tiendo pues a preferir esta expresión de "significante no fonemático" 48 porque no restringe su alcance a la imagen, incluye el sonido, cuya importancia capital ya mencionamos.

Como se sabe, la articulación fonemática de un significante puede remitir a muchos significados, el sentido solo se despliega plenamente en la relación que un significante entabla con otros significantes y eso es igualmente válido para el significante no fonemático.

\subsection{El montaje}

El efecto Kuleshov, derivado del nombre del cineasta y teórico ruso, revela perfectamente eso a través del montaje: el mismo plano corto del rostro del actor Mozzhujin, inexpresivo, es precedido sucesivamente por un plato de sopa, por un cadáver en un ataúd y por una mujer recostada, formando así tres secuencias diferentes. El espectador traduce la expresión de Mozzhujin cada vez en función de la secuencia por un sentimiento de hambre, de tristeza o de deseo.

Por su parte, Godard nos dice "no es una imagen única, sino únicamente una imagen”. Una imagen nunca está sola. Lo que cuenta es la relación entre imágenes. La imagen-movimiento solo se convierte en potencialmente única, solo adquiere valor de "verdad" cuando se pone en relación con las otras imágenes de la película. Y finalmente, no adquiere su pleno valor sino como parte de un todo, en tanto que la parte revela algo del todo, de la entidad que constituye la película, incluso de la obra del autor en su conjunto. A veces, un plano puede esclarecerse plenamente no solo en relación con todas las otras imágenes-movimiento, sino también y sobre todo cuando se conoce la integralidad de la obra del autor; montaje de la película, construcción de la obra.

Es evidente que, como en cualquier otra creación, hay fracasos, lo que no impide de ningún modo que todo sea pesado, pensado y sentido en una película que se inscribe en un proceso de investigador que construye una obra. ${ }^{49}$

\subsection{El encuadre}

Cuando Dreyer filma a Renée Falconetti, en La pasión de Juana de Arco (1927), y la encuadra en un plano corto (un gran plano), de los más bellos y conocidos en la historia del cine, lo que permite ver y sentir nunca había sido visto ni sentido por el ser humano.

"Con el primer plano se ensancha el espacio y bajo el retardador se alarga el movimiento. En una ampliación no sólo se trata de aclarar lo que de otra manera no se vería claro, sino que más bien aparecen en ella formaciones estructurales del todo nuevas. Y tampoco el retardador se limita a aportar temas conocidos del movimiento, sino que en éstos descubre otros enteramente desconocidos que "en absoluto operan como lentificaciones de movimientos más rápidos, sino propiamente en cuanto movimientos deslizantes, flotantes, supraterrenales»".50 
El encuadre nos permite mirar el rostro de Renée Falconetti en una proximidad y una distancia que despliega una "profundización (...) de nuestra percepción" 51

No se trata de la percepción del rostro -"El propósito del arte, con los medios materiales, es arrancar el percepto a las percepciones del objeto" 52 - sino de estar en ese rostro y fundirse en él. Estar en ese rostro como uno estaría en "un bloque de sensaciones compuesto por perceptos y afectos". Se ve y se siente una carga condensada e inefable. "La obra de arte es un bloque de sensaciones, es decir, un compuesto de perceptos y afectos. Los perceptos ya no son percepciones, son independientes de un estado de quienes los experimen$\tan "{ }^{33}$, pues "la obra de arte es un ser de sensación, y solo eso: existe en sí misma." ${ }^{54}$

Quisiera dar testimonio, muy brevemente, de esa potencia del arte cinematográfico a partir de una puesta en paralelo con una de mis prácticas clínicas. En la Maison Verte, lugar en el cual reciben a niños de entre 0 y 4 años, la dimensión fenomenológica se aplica constantemente, en el centro de nuestra práctica de psicoanálisis. Por eso, lo que permite ver y sentir una película como Recreación, o como Ser y tener ${ }^{5 s}$, a partir de los movimientos de los cuerpos de esos niños, la manera en que sus problemáticas psíquicas producen y atraviesan esos movimientos de los cuerpos, nunca podríamos experimentarlo, apreciarlo, verlo y sentirlo con tanta agudeza; una presencia tal de esos cuerpos que no convoca a nuestros cuerpos en una interacción, sino que deja todo el lugar al afecto, a las sensaciones y también al pensamiento. También al pensamiento en el sentido de que podemos ver y volver a ver esas imágenes tanto como materia de reflexión como de perceptos, y que pueden ser convocadas a voluntad para pensarlas.

\section{Conclusión: la confluencia de miradas}

$$
\begin{array}{r}
\text { "Si usted busca lo que, en realidad, es más real que } \\
\text { la realidad misma, hágalo por el lado de la ficción } \\
\text { cinematográfica" } \\
\text { (Slavoj Zizek) }
\end{array}
$$

Lo que caracteriza la obra de arte es esa singularidad afirmada, esa brecha que abre por ser única, diferente a cualquier otra, pues se inscribe en un universo propio del autor, de su mirada, y posee ella misma su propio universo, a la vez que concierne a lo universal porque identifica un efecto de la realidad, lo alcanza o lo penetra en un punto y de una forma como ninguna otra podría hacerlo.

El arte cinematográfico tiende a identificar puntos de lo inefable a través de la imagen-movimiento. Puntos de lo inefable: lo que las palabras no pueden decir, o que dicen de otro modo. En el plano fenomenal se desarrollan, a través de la imagen-movimiento y del ordenamiento de los significantes no fonemáticos, confluencias, accidentes, estados de cambio, deseo en movimiento que se ven y se sienten en una temporalidad -con la cadencia dada por la elipsis- y una espacialidad en el seno de las cuales la condensación, el desplazamiento, el punto de vista ocupan un lugar esencial. ${ }^{57}$

La unión entre investigador psicoanalista y obra cinematográfica a la que apuntamos es la manera en que la obra va a identificar un mismo punto de imposibilidad, un efecto de realidad, a través de herramientas intrínsecas a la investigación y a la expresión artística. Y quizás más aún, aunque menos frecuentemente, lo que la obra ha identificado y que el psicoanalista no pudo captar o no lo pudo hacer de otro modo que a través del lenguaje cinematográfico que emana de la mirada del autor de esa obra.

"Así es como resulta perceptible que la naturaleza que habla a la cámara no es la misma que la que habla al ojo. Es sobre todo distinta porque en lugar de un espacio que trama el hombre con su consciencia presenta otro tramado inconscientemente. Es corriente que pueda alguien darse cuenta, aunque no sea más que a grandes rasgos, de la manera de andar de las gentes, pero desde luego que nada sabe de su actitud en esa fracción de segundo en que comienzan a alargar el paso. Nos resulta más o menos familiar el gesto que hacemos al coger el encendedor o la cuchara, pero apenas si sabemos algo de lo que ocurre entre la mano y el metal, cuanto menos de sus oscilaciones según los diversos estados de ánimo en que nos encontremos. $Y$ aquí es donde interviene la cámara con sus medios auxiliares, sus subidas y sus bajadas, sus cortes $y$ su capacidad aislativa, sus dilataciones y arrezagamientos de un decurso, sus ampliaciones y disminuciones. Por su virtud experimentamos el inconsciente óptico, igual que por medio del psicoaná- lisis nos enteramos del inconsciente pulsional." 58

Si bien no se puede reducir el inconsciente freudiano al "inconsciente pulsional" y la fórmula de "inconsciente óptico" nos parece psicoanalíticomórfica, lo que retenemos del paralelismo de Benjamin es haber visto muy tempranamente que psicoanálisis y cine abrían campos de mirada y de escucha de lo que hasta ese momento no podía ser visto y oído. Y que esos campos pueden ser poderosamente complementarios.

Es por eso que me atrae mucho la idea de que ligar armoniosamente cine y psicoanálisis es abrir una doble 
distancia focal. Dos distancias focales que cuando confluyen tienden a articular lo visible con lo invisible. Lo invisible de las problemáticas inconscientes con lo visible que abre la imagen-movimiento. El psicoanálisis atrapa a través de lo invisible lo inexplicable en lo visible, el cine hace visible y sensible lo que no podría serlo sin él.

En consecuencia, lo invisible que el cine puede hacer visible solo se vuelve inteligible gracias a la confluencia de las dos miradas. Mirada del cineasta, que permite ver y sentir a través de la escritura fílmica. Mirada del espectador, actor, activo, investigador, que se devela en el encuentro con la mirada del autor. ${ }^{59} \mathrm{El}$ efecto de confluencia compromete entonces necesariamente la subjetividad del espectador y la del investigador. Quien dice mirada dice subjetividad. Por eso me parece justo concluir con una apertura: Serge Daney decía "una película nos concierne por lo menos en la misma medida en que la miramos" 60

Mirar una película es potencialmente subjetivante. Las películas que miramos nos conciernen, nos reflejan y nos alteran.

Esas películas que nos conmueven no nos conciernen como idénticos, su mirada no remite a lo mismo, que fija y vuelve estático. Si hay confluencia profunda, conmovedora, es porque esas películas nos alteran. Conciernen nuestra alteridad, extraña a nosotros mismos.

En ese sentido, concordamos con Guattari cuando dice que "el cine es el psicoanálisis contemporáneo de las masas". ${ }^{61}$

\section{Traducción: Estela Consigli}

1 W. Benjamin,., «L'œuvre d'art à l'époque de sa reproductibilité technique», 1939, in CEuvres III, Paris, Gallimard, 2000. [En español: W. Benjamin, La obra de arte en la época de su reproductibilidad técnica, en W. Benjamin, Discursos Interrumpidos I, Taurus, Buenos Aires, 1989]. https://monoskop.org/images/9/99/Benjamin_Walter_La_obra_de_arte_en_la_epoca_de_su_reproductibilidad_tecnica.pdf]

2 El cine que nos interesa aquí no es pues el que domina ampliamente, el de la industria, sino el cine de autor, susceptible de producir obras de arte.

«Freud et l’ «intuition cinégraphique »: psychanalyse, cinéma et épistémologie » in CiNéMAS, vol. 14, n 2-3, 2008, p. 56.

$4 \quad$ P.J. Bouyer y S. Bouyer, (2002). "Cinéma et psychanalyse », in Mijolla de, A., (ed) Dictionnaire international de la psychanalyse, París, Calmann Lévy, p. 325.

5 Petit Robert, 2008. La noción de “impresión” nos remite inevitablemente a la de dominación. [N. de T.: En francés, “empreinte” (impresión) - “emprise” (dominación, influencia, control)].

6 S. Mijolla-Mellor de, (2002). Psychanalyse appliquée/interactions de la psychanalyse, Mijolla de, A. (ed), Dictionnaire international de la psychanalyse, Paris, Calmann-Lévy.

$7 \quad$ Ibid. pág. 1356.

8 Qu'est-ce que la philosophie?, París, Minuit, 1991 [En español: Gilles Deleuze y Félix Guattari, ¿Qué es la filosofía?, , Anagrama, Barcelona, 1993].

$9 \quad$ Mijolla-Mellor de, S., op. cit. pág. 1357.

10 Freud, S., Abraham, K., «Lettre du 9 juin 1925 », en Correspondance Freud-Abrabam, París, Gallimard, coll. «Connaissance de l'inconscient », 1969. [En español: Freud-Abraham. Correspondencia completa. 1907 - 1926, Síntesis, Madrid, 2001].

11 Entiendo aquí este término en el sentido de inanimado, y no -por supuesto- como objeto de la pulsión.

12 Recordemos la conocida fórmula de Lacan: “La esquizia del ojo y de la mirada”, es decir, la imposibilidad de reducir la mirada a la visión. J. Lacan, Le Séminaire, Livre XI, Les quatre concepts fondamentaux de la psychanalyse, París, le Seuil, 1973, pág. 65. [En español: Los cuatro conceptos fundamentales del psicoanálisis, El Seminario, Libro XI, Buenos Aires, Paidós, 1987].

13 G. Deleuze, L'image-mouvement, París, Minuit, 1983. [En español: G. Deleuze, La imagen-movimiento. Estudios sobre cine 1, Buenos Aries, Paidós, 1984].

14 Escribo “cuerpo-psique” para subrayar que el cine capta especialmente la psique a través del cuerpo, y a la vez para destacar -en modo inverso- el innegable lazo entre psique y soma.

15 Ambos descompondrán la marcha, el salto, la carrera de hombres y mujeres para penetrar los movimientos que antes no podían distinguirse. Muybridge confirmará, gracias a su dispositivo, las hipótesis de Marey, quien afirmaba que las patas del caballo, en las fases del galope, solo dejan juntas el suelo una sola vez, algo discutido por los científicos de la época hasta esa descomposición por imagen-movimiento. 
16 En la tradición de ese punto de partida, es interesante señalar una dimensión que puede parecer relativamente anecdótica, y que -quizás- no lo es tanto. Que el descubrimiento analítico parta del incomprensible cuerpo de la histérica tiene, en esa puesta en paralelo, algo de gracioso. La histeria constituye el modo de funcionamiento psíquico que calza como un guante en la función del actor. Desde la relación de la histérica con la imagen del cuerpo, y por lo tanto, con la puesta en escena del cuerpo, hasta -más importante aún- ese deseo del deseo del otro que basa su relación con el otro y consigo mismo, la histérica es, por así decirlo, actriz "nata”. Numerosos sujetos histéricos encontrarán en el arte cinematográfico de ficción material que servirá de materia de creatividad para elucidar la realidad.

17 Benjamin, W., op.cit., págs. 300-301. [En español: W. Benjamin., op.cit., pág. 13].

18 Ibid., pág. 304. [En español: Ibid., pág. 15].

19 Sin embargo, aunque deja suponer ampliamente la complementaridad de ambos campos, es un punto que no desarrollará.

20 Para quienes duden de que el cine puede captar algo de eso, en esta aproximación no muy ortodoxa a la realidad, podrían citarse numerosas secuencias. Me remito a una: vea o vuelva a ver la escena de violación en Irreversible (2002), de Gaspar Noé, y la manera en que ese "imposible" se muestra y se siente como insoportable.

21 W. Benjamin, op.cit., págs. 303-304. [En español: W. Benjamin., op.cit., págs. 14-15].

22 G. Debord (1967), La Société du spectacle, París, Folio, 1992. [En español : G. Debord, La sociedad del espectáculo, in Revista Observaciones filosóficas, Madrid 1987]. (http://www.observacionesfilosoficas.net/download/sociedadDebord.pdf)]

23 Ver en este punto Jacques Rancière, Le spectateur émancipé, París, La fabrique, 2008. [En español, J. Rancière, El espectador emancipado, Ed. Manantial, Buenos Aires, 2010].

$24 \quad$ Lo que no significa que el cine cautivo de la industria no sea interesante para analizar. Conviene hacerlo sobre otras coordenadas: por ejemplo, teniendo en cuenta el dispositivo social en el cual se inscribe y que sirve para perpetuar, más que para subvertir.

$25 \quad$ Nos referimos a lo que la nouvelle vague ha llamado política de autores.

26 R. Dadou, Cinéma, psychanalyse et politique, París, Séguier, pág. 53.

$27 \quad$ P. Mérigeau, Mankiewics, París, Denoël, 1993.

28 Citado por R. Dadoun, op. cit., pág. 47. El subrayado es mío.

29 Freud, Les délires et les rêves dans la Gradiva de Jensen, 1907, París, Gallimard, 1990, p. 141. El subrayado es mío. [En español: S. Freud, Obras Completas de Sigmund Freud, Ordenamiento de James Strachey, Volumen IX (19061908). El delirio y los sueños en la "Gradiva» de W. Jensen y otras obras, El delirio y los sueños en la "Gradiva» de W. Jensen (1907 [1906]), Amorrortu Editores, Buenos Aires, 1976].

30 Kyrou, A. : Luis Bunuel, CINEMA D'AUJOURD'HUI No: 4. París, Seghers, 1962.

31 Op. cit. p. 243-244. El subrayado es mío. [En español: op. cit., pág. 76].

32 Ingmar Bergman, Laterna magica, París, Folio, 2001, págs. 12-13.

33 Asimismo, habría que hacer y profundizar un paralelo entre la ficción cinematográfica y el trabajo de ficcionalización inevitable y necesario para la escritura de casos. Creo que aportamos elementos a esta cuestión, si bien indirectamente.

34 Tal denominación apunta asimismo a diferenciar ese registro del imaginario de aquel al cual quizás se lo ha reducido: el imaginario como ilusión o engaño.

35 L'Institution imaginaire de la société, París, Seuil, 1975, págs. 7-8.

36 S. Freud , (1916-17). Introduction à la psychanalyse, París, Payot, 1974, p. 354. [en español: S. Freud, Obras completas d Sigmund Freud, conferencias de introducción al psicoanálisis, Ordenamiento de James Strachey, Parte III, (1916 - 1917), Volumen XVI, Amorrortu Editores, Buenos Aires, 1976].

37 P. L. Assoun, «Traité de l'œuvre psychanalytique » in Dictionnaires des œuvres psychanalytiques, París, PUF, 2009, pág. 81. El trabajo realizado por Paul-Laurent Assoun sobre las metáforas freudianas es edificante al respecto (págs. 81 a 109).

38 In Qu'est-ce que la philosophie, op. cit. p. 154 à 188. [En español: op. cit. ]

39 Generalmente, pues ciertos cineastas pueden, en especial, hacer solo un esbozo de guión, luego pasar al rodaje y mezclar directamente la escritura de guion con la escritura fílmica.

40 Para un trabajo más profundo sobre el lenguaje fílmico remito especialmente a los trabajos de Daniel Weyl, Septième art: $d u$ sens pour l'esprit, París, L'Harmatan, 2006. Souffle et matière. La pellicule ensorcelée, París, L’Harmatan, 2010.

${ }^{41}$ Deleuze distingue tres variedades de imagen-movimiento: la imagen percepción, la imagen-acción y la imagen-afecto. (En L'image-mouvement, op.cit.). Nuestro trabajo de articulación se realiza esencialmente en torno al movimiento, por lo que no evocaré aquí L'image-temps, que complicaría nuestro propósito inútilmente, Sobre todo porque hoy tiendo a suscribir ciertas críticas que conciernen a esta diferenciación -imagen-movimiento / imagen-tiempo- en que tiempo y espacio están intrínsecamente ligados. Sin 
embargo, precisemos que la imagen-tiempo remite para Deleuze a la propia sustancia del tiempo, independientemente de cualquier acción, un poco de "tiempo en estado puro" dice él en referencia a Proust (L'image-temps, París, Minuit, 1985); no excluyo extender mi reflexión sobre es otra dimensión en una investigación futura.

42 Recordemos que el logos no remite solo a la palabra, a la razón o a la ciencia, sino también a la relación, a la puesta en relación.

43 Observemos que, en esta época en que las series se vuelven cada vez más creativas, al menos desde Lynch con Twin Peaks (1990), y su potencia expresiva reside en gran parte en la duración, el cine conserva la frescura de esa forma de "bybris" de la condensación. Aunque evidentemente la condensación se aplica con fuerza en ese modo de expresión fílmica, nunca -me parece- lo hace en la misma medida ni con la misma potencia cualitativa que en las grandes obras cinematográficas.

${ }_{44}$ G. Deleuze, F. Guattari, Mille Plateaux, París, Editions de Minuit, 1980.

45 Metz, C., Le Signifiant imaginaire, París, Christian Bourgois, 1979.

46 Puede verse este cortometraje de 3.30 minutos en Daylimotion: http://www.dailymotion.com/video/x215z7_le-ptit-bal_music. Enlace verificado el 1 de marzo de $2017 .$.

$47 \quad ¿$ Las primeras expresiones del significante no fonemático no toman cuerpo, por otra parte, en el primer espejo del ser, el rostro de la madre?

48 Según mi conocimiento, la primera que utilizó esta expresión fue Julia Kristeva en La révolution du langage poétique [La revolución del lenguaje poético] (1974).

49 Lo que no significa que las películas cautivas de la industria no sean interesantes para analizar. Conviene hacerlo en base a otras coordenadas: por ejemplo, teniendo en cuenta el dispositivo social en el cual se inscribe y que sirve a perpetuar más que para subvertir.

50 W. Benjamin, op.cit., pág. 305. [En español: W. Benjamin, op.cit., pág. 15].

51 W. Benjamin, op. cit., pág. 303. [En español: W. Benjamin, op.cit., pág. 14].

52 G. Deleuze, F. Guattari, Qu’est-ce que la philosophie, op. cit., p. 158. [En español: G. Deleuze y F. Guattari, ¿Qué es la filosofía ?, op. cit.)].

53 Ibid., pág. 154. [Ibid.]

54 Ibid., pág. 155. [Ibid.]

55 Respectivemente, de Claire Simon (1993) y de Nicolas Philibert (2002).

56 Slavoj Zizek en su documental Le guide pervers du cinéma (2006).

57 Me refiero con esta larga frase a un punto que dejo a la eventualidad de una investigación futura. Muy probablemente, hay cuestiones que se prestan más a efectos de confluencia entre cine y psicoanálisis. Las que conciernen al cuerpo, a la imagen, a la imagen del cuerpo, al narcisismo y a lo que las imágenes cinematográficas contienen en abundancia: confluencias, accidentes -buenos y malos-, estados de cambio...

58 W. Benjamin, op. cit., pp. 305-306 [En español: W. Benjamin, op. cit., pág. 15].

59 Sobre ese “espectador" activo, investigador, pensador y emancipado de La sociedad del espectáculo de Debord, ver: Marie José Mondzain, Homo Spectator, Bayard, París, 2007. Jacques Rancière, Le spectateur émancipé, La Fabrique, París, 2008.

60 P. A. Boutang, D. Rabourdin, Serge Daney - Itinéraire d'un ciné-fils, documental, París, Montparnasse, 2004.

[N. del T.: Juego de palabras en francés con «regarder», que significa a la vez «mirar»y «concernir»: « un film ça nous regarde au moins autant qu'on le regarde»]

61 Citado por Serge Daney, ibid. 